\title{
TRITIUM LOADING IN ITER PLASMA-FACING SURFACES AND ITS RELEASE UNDER ACCIDENT CONDITIONS*
}

\author{
G. R. Longhurst, R. A. Anderl, and R. J. Pawelko, Idaho National Engineering Laboratory \\ PO Box 1625, Idaho Falls, Idaho, 83415, USA
}

\section{AlIs 221096 \\ I. Introduction

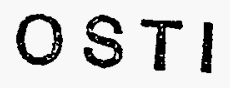

Plasma-facing surfaces of the International Thermonuclear Experimental Reactor (ITER) will take up tritium from the plasma. These surfaces will probably consist of mixtures of $\mathrm{Be}, \mathrm{C}$, and possibly $W$ together with other impurities. Recent experimental results have suggested mechanisms, not previously considered in analyses, by which tritium and other hydrogen isotopes are retained in $\mathrm{Be}$. This warrants revised modeling and estimation of the amount of tritium that will be deposited in ITER beryllium plasma-facing surfaces and the rates at which it can be released under postulated accident scenarios. In this paper we describe improvements in modeling and experiments planned at the Idaho National Engineering Laboratory (INEL) to investigate the tritium uptake and thermal release behavior for mixed plasma-facing materials. TMAP4 calculations were made using recent data to estimate first-wall tritium inventories in ITER.

\section{The Problem}

The present design of plasma facing surfaces in the International Thermonuclear Experimental Reactor (ITER) calls for surfaces with the highest heat and particle loadings to be carbon-fiber composite (CFC) material $\left(35 \mathrm{~m}^{2}\right)$, those of lower but.still high particle and heat fluxes to be of $\mathrm{W}\left(330 \mathrm{~m}^{2}\right)$, and low-flux, low-heat surfaces to be of $\mathrm{Be}\left(1200 \mathrm{~m}^{2}\right)$. CFC has a high enough sputter yield that we may expect much of the Be surface to be coated with carbon. It is not yet known in detail what chemical reactions will occur at the $\mathrm{C} / \mathrm{Be}$ interface, but depending on the carbon thickness and the implanting ion and neutral energies, deposition of tritium on those surfaces may be in the sputtered $\mathrm{C}$, in the Be substrate, or near the Be-C interface. Little is known of the characteristics for release of tritium from mixed-material structures under thermal excursion conditions associated with a potential ITER accident.

\footnotetext{
"Work performed for US Department of Energy, Office of Energy Research under DOE Idaho Field Office Contract DE-AC07-94ID13223.
}

DISTRIBUTION OF THIS DOCUMENT IS UNLMITED
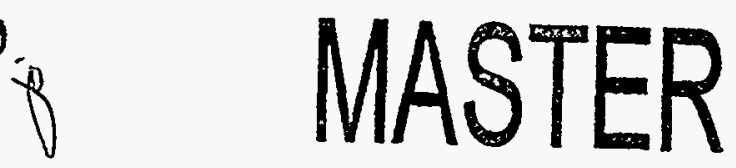


\section{DISCLAIMER}

Portions of this document may be illegible in electronic image products. Images are produced from the best available original document. 
Recently, experiments in the Russian Federation and in the USA have revealed complex and interesting processes involving implanted hydrogen isotopes at high flux densities and bare beryllium surfaces at elevated temperatures. These are conditions representative of ITER baffles and startup limiter. Results cast new light on mechanisms by which tritium will be retained and released from such surfaces, rendering some existing models obsolete.

The studies described here are to help answer questions of how much tritium inventory may be associated with such structures, and what tritium source term must be considered in ITER safety analyses.

\section{Observations}

Beryllium - Mayer et al.[1] showed that sputtered $\mathrm{Be}$ deposits as $\mathrm{BeO}$ and that deuterium (and by inference tritium) is retained in $\mathrm{BeO}$ in almost the same proportions as it is with $\mathrm{C}$ ( 0.38 $\mathrm{D} / \mathrm{BeO}$ vs. $0.41 \mathrm{D} / \mathrm{C}$ ). Chernikov et al.[2], Guseva et a1.[3], and Markin et al.[4] have demonstrated experimentally that hydrogen atoms or ions injected into beryllium begin to collect in small bubbles of diatomic gas after fluences of $1 \times 10^{22} \mathrm{ion} / \mathrm{m}^{2}$. Those bubbles begin near the implantation depth and propagate toward the surface with continued fluence, saturating at gas molecule fractions of a few percent. When saturation occurs, interconnected porosity opens releasing tritium to the surface. Simultaneously, as observed by Guseva et a1.[3] and by Anderl et al.[5][6], defects induced by ion energies propagate to many times the ion stopping range providing additional reservoirs for tritium.

Carbon - Modeling tritium retention in pure $\mathrm{C}$ exposed to plasma is relatively straightforward. It will deposit up to the implantation depth or a little beyond, forming an amorphous $\mathrm{CH}$ phase. Diffusion will be very slow with a diffusion activation energy in excess of $4 \mathrm{eV}$. We expect that tritium deposited into a Clayer on Be will exhibit the same characteristics. However, if the $\mathrm{C}$ interacts chemically with the $\mathrm{Be}$ substrate forming $\mathrm{Be}_{2} \mathrm{C}$, properties may be much different. We know that doping the surface of graphite with $B$ alters the retention characteristics for $\mathrm{H}$ isotopes, [7] but there is little if anything known of the effects of $\mathrm{W}$ or $\mathrm{Be}$ impurities on $\mathrm{H}$ retention characteristics of $\mathrm{C}$ surfaces.

Tungsten - Previous implantation experiments with W [8][9] have given sufficient information to estimate with reasonable assurance the inventories to be expected and the release kinetics for tritium in components made from ordinary $W$. If plasma-sprayed $W$ is used, unless it is formed at very high density, the $\mathrm{W}$ will be a porous screen, and except for trapping in the $\mathrm{W}$ 
grains, permeation characteristics will depend on the substrate under the W.[10] It is not yet known how $C$ films will effect release of tritium from $W$.

Essentially all of the studies conducted to date have been made on materials unirradiated by neutrons, although some studies have previously been done on neutron-irradiated Be.[11][12] It is not yet fully known how defects induced by neutron irradiation, especially in a fusion-neutron environment, will affect tritium retention in any of these materials.

\section{Experimental System}

The INEL ion implantation experimental apparatus described previously[13][14] was modified by replacing the target chamber with one that allows test samples to be installed, rapidly heated and cooled, and removed to a secondary vacuum chamber, all under high vacuum. Figure 2 shows the fixture for holding and heating the $2-\mathrm{cm}$ diameter specimens.

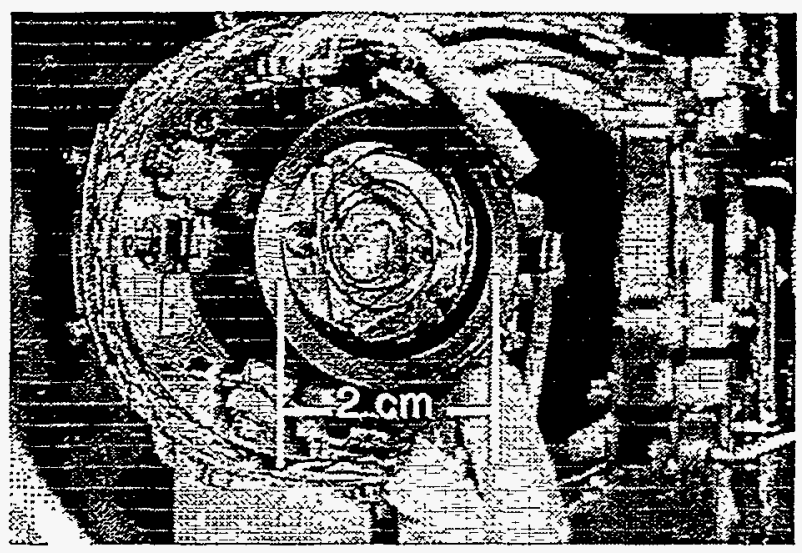

Figure 2. Sample holder in modified ion implantation facility at the INEL.

Binary mixtures of carbon/beryllium are prepared by sputter-deposition of carbon onto beryllium substrates. The specimens are heat treated to create a mixed composition. Specimen coatings are characterized using electron microscopy and Auger spectrometry. Subsequently, each specimen is heated in the target chamber, implanted with deuterium, and cooled quickly to retain the injected deuterium. Specimens are then transferred to the secondary chamber under vacuum, and the deuterium release is observed using a quadrupole mass spectrometer during a thermal ramp. Implantation temperatures range from $570 \mathrm{~K}$ to $770 \mathrm{~K}$ with deuterium ion energies of $1 \mathrm{keV} / \mathrm{D}$ and $200 \mathrm{eV} / \mathrm{D}$.

\section{Modeling}

The TMAP4 Code[15] has been used successfully to simulate recent experimental results on the Tritium Plasma Experiment[16] by accounting for the processes of surface erosion, bubble formation and saturation (resulting in opening of porosity), and the more usual diffusion and trapping. Using this code it is estimated that the baffles on ITER will hold and inventory of 0.41 $\mathrm{g}$ of tritium after $3 \times 10^{6}$ seconds of operation. Diffusion will have progressed only $1 \mathrm{~mm}$ 
through the $\mathrm{Be}$. Tritium in the first wall will all be as codeposited gas with $\mathrm{BeO}$ and $\mathrm{C}$. If only $1 \%$ of the Be sputtered off the baffles deposits on the first wall, and it loads to its saturation concentration of 0.38 , the tritium inventory in the first wall would be over $1 \mathrm{~kg}$. This is highly speculative however. Estimates for W and CFC surfaces are in progress.

\section{Conclusions}

There is an urgent need for additional information on tritium retention and release characteristics for mixed materials. Present models are capable of making tritium estimates for some ITER components, but not for the first wall, where inventories are potentially the greatest. Experiments underway at the INEL and on the TPE will help resolve these issues.

\section{References}

1. M. Mayer, R. Behrisch, H. Plank, J. Roth, G. Dollinger, and C. M. Frey, "Codeposition of Hydrogen with Be, C and W, " to be published in J. Nucl.Materials.

2. V. N. Chernikov et al., J. Nucl. Materials 228, No. 1, 47-60 (1996).

3. M. I. Guseva et al., in: Proc. 2nd IEA Int'l. Workshop on Beryllium Technology for Fusion, CONF-9509218, 315-331 (Sep. 1995).

4. A. V. Markin et al., in: Proc. 2nd IEA Int'l. Workshop on Beryllium Technology for Fusion, CONF-9509218, 332-347 (Sep. 1995)

5. R. A. Anderl et al., J. Nucl. Materials, 196-198, 986-991 (1992).

6. R. A. Anderl et al., Proc. 5th Int'l. Conf. Hydrogen Effects on Mat'l. Behavior, Jackson Lake Lodge, Moran, WY, September 11-15, 1994; also in INEL-94/00036. (October 29,1994).

7. V. Fernandez et al., J. Nucl. Materials, 196-198, 1022-1026 (1992).

8. R. A. Anderl et al., Fusion Technology 21, 745-752 (1992).

9. T. J Dolan, , ITER/US/95/TE/SA-5, Rev. 1 (May 4, 1995).

10. R. A. Anderl et al., J. Nucl. Materials, 212-215, 1416-1420 (1994).

11. R. A. Anderl et al., Fusion Technology, 28, 1114 -1119 (1995).

12. D. L. Baldwin and M. C. Billone, J. Nucl. Materials, 212-215, 848-953 (1994).

13. R. A. Anderl et al., Fusion Technology 8, 2299-2305 (1985).

14 R. A. Anderl et al., in: Proceedings of 11th Symposium on Fusion Engineering, IEEE Cat. No. CH2251-7, 644-649 (1985).

15. G. R. Longhurst, TMAP4 User's Manual, EGG-FSP-10315 (June 12, 1992).

16. R. A. Causey et al., this conference.

\section{DISCLAIMER}

This report was prepared as an account of work sponsored by an agency of the United States Government. Neither the United States Government nor any agency thereof, nor any of their employees, makes any warranty, express or implied, or assumes any legal liability or responsibility for the accuracy, completeness, or usefuiness of any information, apparatus, product, or process disclosed, or represents that its use would not infringe privately owned rights. Reference herein to any specific commercial product, process, or service by trade name, trademark, manufacturer, or otherwise does not necessarily constitute or imply its endorsement, recom-

I mendation, or favoring by the United States Government or any agency thereof. The views and opinions of authors expressed herein do not necessarily state or reflect those- of the United States Government or any agency thereof: - - 